\title{
ESTOQUE DE BIOMASSA E CARBONO EM PASTAGENS CULTIVADAS NO NORTE DE RONDÔNIA
}

\author{
BIOMASS AND CARBON STOCKS OF CULTIVATED PASTURE \\ IN NORTHERN RONDONIA
Carlos Roberto Sanquetta ${ }^{1}$, Alexis de Sousa Bastos ${ }^{2}$, Mateus Niroh Inoue Sanquetta ${ }^{1}$, Paulo Henrique Corrêa Korbela do Rosário ${ }^{1}$, Ana Paula Dalla Corte ${ }^{1}$, Luani Rosa de Oliveira Piva ${ }^{1}$
${ }^{1}$ Universidade Federal do Paraná, Curitiba, Paraná, Brasil - carlossanquetta@gmail.com, mateus.sanquetta@gmail.com, phcorreakr@gmail.com, anapaulacorte@gmail.com \& luanipiva@yahoo.com.br
${ }^{2}$ Centro de Estudos Rioterra, Porto Velho, Rondônia, Brasil-alexis@rioterra.org.br

RESUMO

\begin{abstract}
A substituição da vegetação natural da Floresta Amazônica por pastagens cultivadas é uma realidade há décadas. A hipótese que se estabelece neste estudo é que a substituição de floresta tropical por pastagens implica em balanço negativo de biomassa e carbono e emissões expressivas de GEE. Existem muitos estudos sobre biomassa e carbono estocados em floresta natural, porém poucos em pastagens cultivadas em Rondônia. Por isso, objetivou-se determinar os estoques de biomassa e de carbono na região. Vinte unidades amostrais de $1 \mathrm{~m}^{2}$ alocadas aleatoriamente em fazendas de pecuária manejadas com Urochloa brizantha nos municípios de Itapuã do Oeste e Cujubim foram instaladas. Toda a biomassa foi amostrada até a máxima profundidade das raízes no quadrilátero circunscrito. A biomassa fresca foi pesada e amostras de cerca de $1 \mathrm{~kg}$ foram coletadas para determinação da biomassa seca e do teor de carbono. O estoque de biomassa seca resultante foi de $18,90 \mathrm{Mg} \mathrm{ha-1}$ em média, com

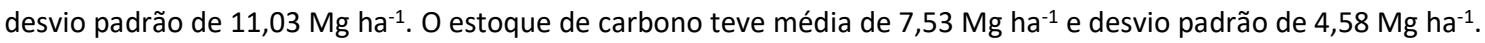
O teor médio de carbono foi de 39,35\%, com desvio padrão de 5,32\%. Considerando o estoque de carbono na biomassa vegetal na floresta natural madura, de $180,00 \mathrm{Mg} \mathrm{ha}^{-1}$ (dado da literatura), pode-se concluir que houve perda de $172,47 \mathrm{MgC} \mathrm{ha}^{-1}$, o que corresponde a uma emissão líquida de $632,39 \mathrm{MgCO}_{2 \text { eq }}$ ha-1 para a atmosfera. Esse é o impacto predito decorrente da substituição da floresta tropical por pastagens na região.
\end{abstract}

PALAVRAS-CHAVE: Desmatamento, Emissões de Gases de Efeito Estufa, Pecuária, Sudoeste da Amazônia.

\section{ABSTRACT}

The replacement of the natural vegetation of the Amazon Forest with cultivated pastures has been a reality for decades. The hypothesis established in this study is that replacement of tropical forest by pasture implies negative balance of biomass and carbon and significant GHG emissions. There are many studies on biomass and carbon stocked in natural forest, but few in pastures cultivated in Rondônia. Therefore, the objective was to determine the biomass and carbon stocks in the region. Twenty $1 \mathrm{~m}^{2}$ sampling units randomly allocated to livestock farms managed with Urochloa brizantha in the municipalities of Itapuã do Oeste and Cujubim were installed. All biomass was sampled to the maximum root depth in the sampling square. Fresh biomass was weighed and samples of about $1 \mathrm{~kg}$ were collected to determine dry biomass and carbon content. The resulting dry biomass stock was $18.90 \mathrm{Mg} \mathrm{ha}^{-1}$ on

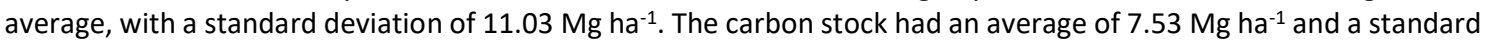
deviation of $4.58 \mathrm{Mg} \mathrm{ha}^{-1}$. The average carbon content was $39.35 \%$, with a standard deviation of $5.32 \%$. Considering $180.00 \mathrm{Mg} \mathrm{ha}^{-1}$ as the standard carbon stock in plant biomass of mature natural forest in the region (literature data), it can be concluded that there was a carbon loss of $172.47 \mathrm{Mg} \mathrm{ha}^{-1}$, which corresponds to a net emission of 632.39 $\mathrm{Mg} \mathrm{ha}{ }^{-1}$ of $\mathrm{CO}_{2 \text { eq }}$ to the atmosphere. This is the predicted impact of replacing the rainforest with pastures in the region.

KEYWORDS: Deforestation, Greenhouse Gases Emissions, Cattle-ranching, Southwestern Amazon. 


\section{INTRODUÇÃO}

O desmatamento na Amazônia é uma realidade há décadas (FERREIRA \& COELHO, 2015). As espécies de madeiras nobres, com maior valor agregado, são as primeiras a serem exploradas. Em seguida, realiza-se a exploração de outras espécies menos valiosas, mas que podem gerar algum lucro. Em seguida, as árvores de menor porte são derrubadas, remanescendo na paisagem alguns exemplares considerados protegidos por lei. O processo de destruição da floresta original culmina com a conversão completa em outras coberturas do solo. Esse processo geralmente pode levar alguns anos até se efetivar por completo.

Estima-se que a área total desmatada da Amazônia Legal desde que o Instituto Nacional de Pesquisas Espaciais (INPE) iniciou o Programa de Monitoramento do Desmatamento da Amazônia (PRODES) no ano de 1998 até 2018 seja de $436.621 \mathrm{~km}^{2}$ (INPE, 2019), o que corresponde a 8,36\% do território em questão. Certamente o percentual de área desprovida de vegetação original é muito maior, devido aos desmatamentos ocorridos antes desse período nos ecossistemas florestais e não florestais nativos do bioma Amazônia.

Estima-se que toda a área desmatada na Amazônia tenha atingido 78 milhões de ha, ou seja, algo próximo de 20\% desse bioma (INPE, 2017; SANQUETTA et al., 2017). Além do desmatamento, a Amazônia é alvo de uma série de atividades antrópicas que promovem a degradação do ecossistema, principalmente nas áreas de fronteira agrícola, reconhecidas como "Arco do Desmatamento", que respondem por $80 \%$ dos desmatamentos na região (FEARNSIDE, 2009).

Rondônia é um dos Estados da Amazônia brasileira com as maiores taxas de desmatamento do país, com cerca de $35 \%$ de seu território desprovido de vegetação nativa, o que corresponde a $83,5 \mathrm{mil} \mathrm{km}^{2}$ (INPE, 2019). Considerando apenas os dados de desmatamento de 1988 a 2018, a taxa de desmatamento no período implica em perda de mais de $25 \%$ da cobertura vegetal do Estado.

Entre os vetores mais importantes de desmatamento na região, destacam-se a pecuária extensiva bovina de corte, praticada há décadas no Estado (BASTOS et al., 2015) e, mais recentemente, a agricultura mecanizada de larga escala, que vem gradualmente substituindo as pastagens já consolidadas e, por vezes, avançando rumo a novas fronteiras de desmatamento (COSTA et al., 2017).

Como a pecuária é uma atividade extensiva e economicamente importante para a região, a Urochloa brizantha (Hochst. ex A. Rich.) R.D.Webster (braquiária) é uma das mais cultivadas em larga escala na Amazônia. Estima-se que cerca de $80 \%$ das áreas de pastagens cultivadas no país estejam ocupadas por genótipos desse gênero, como U. brizantha cv. Marandu (capim-marandu), representando $50 \%$ deste total (CARDOSO et al., 2015; SILVA et al., 2017).

A substituição de floresta nativa por pastagem representa uma perda de estoque de carbono armazenado na vegetação, que implica na emissão de gases de efeito estufa (GEE) pela supressão e eventual queima da biomassa lenhosa. A informação precisa e acurada dos estoques de biomassa e carbono é crucial no cálculo das emissões de GEE em inventários nacionais encaminhados à Convenção-Quadro das Nações Unidas sobre Mudanças Climáticas e aos seus desdobramentos em relação do Acordo de Paris, dos quais o Brasil é signatário. No terceiro inventário de GEE do Brasil foram utilizados valores default do Painel Intergovernamental sobre Mudanças Climáticas (IPCC, 2003) de estoque de carbono em pastagem plantada, de acordo com o Ministério de Ciência, Tecnologia e Inovações (MCTI, 2014). A adoção desse método resulta em incertezas no cálculo das emissões derivadas de mudança no uso do solo, que é a maior fonte acumulada de emissões do país desde o início do seu cômputo em 1990.

A hipótese deste estudo é que a substituição de floresta tropical por pastagens implica em balanço negativo de biomassa e carbono e expressivas quantidades de emissões de GEE. Essa perda de biomassa e carbono deve estar expressa nos inventários de emissões de GEE publicados pelo Brasil aos organismos multilaterais.

Diante desse cenário, este trabalho visou quantificar os estoques de biomassa e carbono em pastagens plantadas no norte do Estado de Rondônia e discutir suas implicações no âmbito das emissões de GEE. Almejou-se, ainda subsidiar, com novas informações, os próximos inventários brasileiros de emissões de GEE.

\section{MATERIAL E MÉTODOS}

Este estudo foi desenvolvido na região Norte do Estado de Rondônia, em particular os municípios de Itapuã do Oeste e Cujubim. A região possui solos classificados como Latossolos Amarelos distróficos (RADAMBRASIL, 1978; RONDÔNIA, 2002), clima do tipo tropical Aw com temperatura média anual entre 24 e $26^{\circ} \mathrm{C}$, e precipitação pluviométrica variando de 2.200 a $2.600 \mathrm{~mm}$ por ano (GAMA, 2002; IBGE, 2006; ALVARES et al., 2014). A vegetação original predominante na região de estudo é Floresta Ombrófila Aberta Submontana (RADAMBRASIL, 
1978; SILVA \& VINHA, 2002; IBGE, 2012).

Para coletar os dados, foram instaladas aleatoriamente 20 unidades amostrais quadradas de $1 \mathrm{~m}^{2}$ em 8 fazendas de pecuária de corte, segundo o método de área fixa (SANQUETTA et al., 2014). As coordenadas das parcelas foram coletadas com um receptor da marca Garmin, modelo GPSMAP64, utilizando DATUM SIRGAS2000 (Tabela 1).

Tabela 1. Coordenadas das unidades amostrais instaladas nas áreas de pastagens.

\begin{tabular}{ccc}
\hline Parcela & Coord. UTM* $\mathbf{X}(\mathbf{m})$ & Coord. UTM* $\mathbf{Y}(\mathbf{m})$ \\
\hline 1 & 477.491 & 8.994 .563 \\
2 & 477.528 & 8.994 .677 \\
3 & 474.410 & 8.994 .910 \\
4 & 473.991 & 8.991 .980 \\
5 & 473.992 & 8.992 .031 \\
6 & 473.316 & 8.992 .437 \\
7 & 473.376 & 8.992 .405 \\
8 & 531.216 & 8.960 .188 \\
9 & 531.148 & 8.960 .171 \\
10 & 531.386 & 8.963 .352 \\
11 & 531.395 & 8.963 .293 \\
12 & 531.467 & 8.963 .277 \\
13 & 531.504 & 8.963 .382 \\
14 & 491.332 & 8.950 .264 \\
15 & 491.409 & 8.950 .267 \\
16 & 491.470 & 8.950 .264 \\
17 & 491.941 & 8.949 .948 \\
18 & 492.079 & 8.949 .944 \\
19 & 492.168 & 8.949 .801 \\
\hline 20 & 492.225 & 8.949 .694 \\
\hline
\end{tabular}

Nas unidades amostrais, toda a biomassa aérea e subterrânea foi coletada cuidadosamente, buscando-se remover todas as raízes circunscritas no quadrilátero e em toda sua extensão de profundidade, bem como retirar o solo aderido nas raízes. A biomassa total (aérea e subterrânea) fresca foi pesada em conjunto no campo com balança de precisão de $10 \mathrm{~g}$.

Amostras de aproximadamente $1 \mathrm{~kg}$ foram coletadas de cada parcela e seus pesos frescos foram determinados em laboratório com balança de precisão de $1 \mathrm{~g}$. As amostras compostas da parte aérea e das raízes foram secas em estufa com circulação de ar a uma temperatura de $70^{\circ} \mathrm{C}$ até peso constante e a biomassa seca dessas amostras foi utilizada para calcular a biomassa seca para toda a unidade amostral, pela expressão (1).

$$
b s=b f \frac{T u}{100}
$$

Em que: $b s=$ biomassa seca da unidade amostral (g); $b f=$ biomassa fresca da unidade amostral (g); e $T u=$ teor de umidade da amostra (\%).

Uma fração das amostras de biomassa seca foi retirada para fragmentação e moagem em moinho tipo Willey, produzindo amostras com gramatura mesh 50 . Em seguida, as amostras compostas da parte aérea e subterrânea foram utilizadas para determinar os teores de carbono, em porcentagem, com o equipamento Leco C-144. O teor de carbono equivalente $\left(\mathrm{CO}_{2 \mathrm{eq}}\right.$, em \%), ou seja, o teor obtido após a conversão de carbono em $\mathrm{CO}_{2}$, foi calculado como descrito pelo IPCC (2003), a partir de uma taxa de conversão de 44/12 multiplicada pelo estoque de carbono, que corresponde ao peso atômico do $\mathrm{CO}_{2}(44)$, dividido pelo peso atômico do carbono (12).

$$
\mathrm{CO}_{2 e q}=\mathrm{C} * \frac{44}{12}
$$

Em que: $\mathrm{CO}_{2 e q}=$ teor de carbono equivalente, em \%; $C=$ teor de carbono, em $\%$.

\section{RESULTADOS E DISCUSSÃO}

Os valores de biomassa seca total estocada nas pastagens variaram de 6,67 a 47,51 $\mathrm{Mg} \mathrm{ha}^{-1}$, com média de $18,90 \mathrm{Mg} \mathrm{ha}^{-1}$ e desvio padrão de $11,03 \mathrm{Mg} \mathrm{ha}^{-1}$ (Tabela 2). Os teores de carbono variaram de $30,39 \%$ a $44,88 \%$, com média de 39,35\% e desvio padrão de 5,32\%.

As variações de estoque de biomassa foram mais expressivas em termos relativos em comparação aos teores de carbono, com coeficientes de variação de $60,86 \%$ e $13,53 \%$, respectivamente. Por conseguinte, o que determinou as maiores variações nos estoques de carbono foi a biomassa estocada. Os estoques de carbono nas unidades amostrais variaram de 2,03 a 19,12 $\mathrm{Mg} \mathrm{ha}^{-1}$, com média de 7,53 $\mathrm{Mg} \mathrm{ha}^{-1}$ e desvio padrão de 4,58 $\mathrm{Mg} \mathrm{ha}^{-1}$. 0 estoque de carbono em questão corresponde à remoção média de dióxido de carbono de 69,29 $\mathrm{MgCO}_{2 \text { eq }} \mathrm{ha}^{-1}$.

$\mathrm{O}$ valor de estoque de carbono publicado pelo IPCC e utilizado no inventário brasileiro de emissões de GEE para pastagem cultivada no bioma Amazônia é de 7,57 $\mathrm{Mg} \mathrm{ha}^{-1}$ (MCTI, 2014), portanto, muito próximo da média de estoque de carbono encontrada neste estudo. Isso corrobora com a assertividade das estimativas de emissões e remoções por mudança no uso da terra no documento oficial publicado pelo governo brasileiro. 
Tabela 2. Teor de carbono, biomassa seca e estoque de carbono nas unidades amostrais instaladas nas áreas de pastagens.

\begin{tabular}{|c|c|c|c|}
\hline $\begin{array}{l}\text { Unidade } \\
\text { amostral }\end{array}$ & $\begin{array}{c}\text { Teor de } \\
\text { carbono (\%) }\end{array}$ & $\begin{array}{l}\text { Biomassa } \\
\left(\mathrm{Mg} \mathrm{ha}^{-1}\right)\end{array}$ & $\begin{array}{l}\text { Carbono } \\
\text { (Mg ha-1) }^{-1}\end{array}$ \\
\hline 1 & 40,24 & 47,51 & 19,12 \\
\hline 2 & 41,65 & 29,87 & 12,44 \\
\hline 3 & 40,15 & 13,40 & 5,38 \\
\hline 4 & 40,74 & 30,60 & 12,47 \\
\hline 5 & 42,94 & 30,70 & 13,18 \\
\hline 6 & 40,67 & 8,13 & 3,31 \\
\hline 7 & 40,81 & 15,52 & 6,33 \\
\hline 8 & 33,85 & 28,60 & 9,68 \\
\hline 9 & 41,01 & 33,39 & 13,69 \\
\hline 10 & 39,35 & 23,30 & 9,17 \\
\hline 11 & 41,82 & 11,90 & 4,98 \\
\hline 12 & 21,35 & 11,60 & 2,48 \\
\hline 13 & 43,33 & 8,50 & 3,68 \\
\hline 14 & 40,62 & 9,40 & 3,82 \\
\hline 15 & 40,01 & 11,73 & 4,69 \\
\hline 16 & 38,35 & 10,62 & 4,07 \\
\hline 17 & 30,39 & 6,67 & 2,03 \\
\hline 18 & 44,88 & 13,27 & 5,96 \\
\hline 19 & 43,37 & 18,03 & 7,82 \\
\hline 20 & 41,37 & 15,19 & 6,28 \\
\hline Média & 39,35 & 18,90 & 7,53 \\
\hline Desvio padrão & 5,32 & 11,03 & 4,58 \\
\hline
\end{tabular}

O valor de teor de carbono desse estudo foi $21 \%$ menor que a publicada pelo IPCC (2006) para pastagem, que é de $50 \%$. Isso tem importantes implicações nos cálculos de estoque de carbono em pastagens em inventários de GEE, sobretudo quando há conversões de floresta para pastagem. No caso do inventário brasileiro, não fica evidente essa influência porque se utilizou diretamente $50 \%$ de teor de carbono para quantificar o estoque de carbono ao invés de teores mais exatos. Entretanto, à medida que níveis de refinamento das estimativas se tornem mais elevados nos inventários brasileiros (Tiers maiores) - o que é desejável - será fundamental rediscutir essa variável e incorporar aos cálculos valores reais obtidos em estudos científicos como os resultados aqui gerados.

As emissões brasileiras de GEE no ano de 2017 atingiram cerca de 2 bilhões de $\mathrm{Mg}$ ano-1 brutos e 1,5 bilhões de $\mathrm{Mg}$ ano-1, considerando as remoções por sumidouros (OBSERVATÓRIO DO CLIMA, 2019). Cerca de $46 \%$ das emissões brutas se devem à mudança no uso da terra, o que equivale a $906 \mathrm{MMgCO}_{2 \text { eq }} \mathrm{ano}^{-1}$. Em termos líquidos, esse valor corresponde a $376 \mathrm{MMgCO}_{2 \text { eq }} \mathrm{ano}^{-1}$ (OBSERVATÓRIO DO CLIMA, 2019). Com esse nível de emissão por mudança no uso da terra, o Brasil atualmente ocupa segundo lugar, atrás da Indonésia, apesar disso, as emissões por desmatamento e práticas relacionadas diminuíram drasticamente nos últimos anos. Contudo, o saldo acumulado de emissões por mudança no uso da terra no período 1990-2017 é expressivo (cerca de 39 bilhões de toneladas brutas de $\mathrm{CO}_{2}$ ).

As emissões de GEE por mudança no uso da terra têm no desmatamento e na degradação florestal o seu maior vetor. Segundo o Observatório do Clima (2019), cerca de 92\% das emissões nesse setor advêm dessas atividades e a maior parte desse desmatamento decorre de conversão de floresta tropical para pastagem cultivada, notadamente braquiária.

Assumindo o valor de estoque de carbono em floresta tropical madura, da ordem de $180 \mathrm{Mg} \mathrm{ha}^{-1}$, com base nas sínteses de literatura realizadas pelo MCTI (2014), a redução do estoque de carbono na biomassa vegetal seria de aproximadamente $96 \%$. Assim, estima-se que a emissão decorrente da substituição de floresta por pastagem seja de $632,29 \mathrm{MgCO}_{2 \text { eq }} \mathrm{ha}^{-1}$. Considerando adicionalmente que houve perda de 8,35 milhões de hectares da floresta original do Estado de Rondônia (INPE, 2017; SANQUETTA et al., 2017), esse processo de desmatamento acarretou na emissão total de mais de $45,28 \mathrm{GMgCO}_{2}$ eq. Esse valor corresponde, aproximadamente, a soma de todas as emissões de GEE no mundo no ano de 2010 (IPCC, 2014).

Outros estudos conduzidos na Amazônia apontam que a conversão de floresta em pastagem - em áreas nas quais o fogo foi utilizado para limpeza do terreno - acarretaram na perda, ao longo de uma década, de até $94 \%$ da biomassa acima do solo (LONGO et al., 2016), além de decréscimos nos estoques de carbono do solo (NAVARRETE et al., 2016) - o qual representa de $30-60 \%$ do total de carbono estocado nos ecossistemas florestais (DON et al., 2011).

As taxas de desmatamento em Rondônia, acompanhando a tendência geral da Amazônia, tiveram redução acentuada até 2012, com picos em 1995 e 2004. Porém, a partir de 2013 voltaram a subir gradualmente (INPE, 2019). Desde 2008 que o Estado de Rondônia não sofria uma aceleração nas taxas de desmatamento com decorrente conversão de floresta para pecuária e, posteriormente, agricultura. Se perdurar essa tendência, e o mesmo ocorrer em outras regiões da Amazônia, haverá risco de aumento das emissões de GEE e possível descumprimento de compromissos internacionalmente assumidos. Somente com o contínuo monitoramento da cobertura florestal e da melhoria das estimativas de biomassa e carbono em florestas e outros usos do solo (pastagem neste caso) será possível confirmar ou não essa 
tendência.

Paralelamente, o país precisa reencontrar o caminho da redução do desmatamento e buscar opções sustentáveis para o uso dos seus recursos naturais. Entre essas opções estão a valorização do manejo florestal madeireiro e não madeireiro e a adoção de sistemas integrados de agricultura, produção animal e florestal.

\section{CONCLUSÕES}

O estoque médio de carbono encontrado neste trabalho é semelhante ao do IPCC para pastagens cultivadas nos trópicos e que foi empregado no último inventário brasileiro de GEE elaborado pelo Governo Federal. Almejou-se, ainda, subsidiar com novas informações os próximos inventários de emissões de GEE.

A substituição de floresta tropical por pastagem reduz drasticamente o estoque de carbono na biomassa vegetal e promove expressivas emissões de dióxido de carbono para a atmosfera.

\section{REFERÊNCIAS}

ALVARES, C.A. et al. Köppen's climate classification map for Brazil. Meteorologische Zeitschrift, v.22, n.6, p.711-728, 2014.

BASTOS, A.S. et al. Vulnerabilidade natural à erosão no Sudoeste da Amazônia associada aos seus modos de ocupação? O caso do entorno da Terra Indígena Uru Eu Wau Wau. Revista Brasileira de Geomorfologia, v.16, p.271-282, 2015.

CARDOSO, J.M.S. et al. Fontes e doses de nitrogênio na produtividade do capim-marandu. Publicações em Medicina Veterinária e Zootecnia, v.9, n.8, p.348-358, 2015.

COSTA, O.B. et al. Spatiotemporal mapping of soybean plantations in Rondônia, Western Brazilian Amazon. Acta Amazônica, v.47, n.1, p.29-38, 2017.

DON, A.S. et al. Impact of tropical land-use change on soil organic carbon stocks - a meta-analysis. Global Change Biology, v.17, p.1658-1670, 2011.

FEARNSIDE, P.M. Aquecimento global na Amazônia: impactos e mitigação. Acta Amazonica, v.39, n.4, p.1003-1012, 2009.

FERREIRA, M.D.P.; COELHO, A.B. Desmatamento recente nos Estados da Amazônia Legal: uma análise da contribuição dos preços agrícolas e das políticas governamentais. Revista de Economia e Sociologia Rural, v.53, n.1, p.93-108, 2015.

GAMA, M.J. Clima. In: Atlas geoambiental de Rondônia. Porto Velho: SEDAM, 2002.

IBGE - Instituto Brasileiro de Geografia e Estatística. Manual Técnico da Vegetação Brasileira. 2.ed. Brasília: IBGE, 2012. Disponivel em: https://biblioteca.ibge.gov.br/visualizacao/livros/ liv63011.pdf
IBGE - Instituto Brasileiro de Geografia e Estatística. Mapar de solos de Rondônia. Brasília: IBGE, 2006. Disponível em: $\mathrm{ftp}$ //geoftp.ibge.gov.br/informacoes_ambientais/pedologia/ma pas/unidades_da_federacao/ro_pedologia.pdf

INPE - Instituto Nacional de Pesquisas Espaciais. Projeto PRODES - Monitoramento da floresta amazônica por satélite. 2017. Disponivel em: http://www.obt.inpe.br/prodes/sisprodes2000_ 2016.htm

INPE - Instituto Nacional de Pesquisas Espaciais. Projeto PRODES - Monitoramento da floresta amazônica por satélite. 2019. Disponível em: http://www.obt.inpe.br/prodes/dashboard/ prodes-rates.html

IPCC - Intergovernmental Panel on Climate Change. Good practice guidance for land use, land-use change and forestry. IPCC National Greenhouse Gas Inventories Programme, UNEP, 2003. Disponível em: https://www.ipcc-nggip.iges.or.jp/public/ gpglulucf/gpglulucf.html

IPCC - Intergovernmental Panel on Climate Change. IPCC Guidelines for National Greenhouse Gases Inventories, chapter 3.4 - Grassland. 2006. Disponível em: https://www.ipccnggip.iges.or.jp/public/gpglulucf/gpglulucf_files/Chp3/Chp3_4_ Grassland.pdf

IPCC - Intergovernmental Panel on Climate Change. Climate Change. AR5 Synthesis Report. 2014. Disponível em: https://www.ipcc.ch/report/ar5/syr/

LONGO, M. et al. Aboveground biomass variability across intact and degraded forests in the Brazilian Amazon. Global Biogeochemical Cycles, v.30, p.1639-1660, 2016.

MCTI - Ministério da Ciência, Tecnologia e Inovação. III Inventário de Emissões e Remoções Antrópicas de Gases de Efeito Estufa. Relatórios de Referência, Emissões no setor uso da terra, mudança do uso da terra e florestas, 2014.

NAVARRETE, D. et al. Conversion from forests to pastures in the Colombian Amazon leads to contrasting soil carbon dynamics depending on land management practices. Global Change Biology, v.22, p.3503-3517, 2016.

OBSERVATÓRIO DO CLIMA. SEEG - Sistema de Estimativa de Emissões e Remoções de Gases de Efeito Estufa. 2019. Disponível em: http://plataforma.seeg.eco.br/

RADAMBRASIL. Levantamento de recursos naturais. Projeto RADAMBRASIL, Folha SC.20 - Porto Velho. DNPM, 1978.

RONDÔNIA. As unidades de conservação de Rondônia. 2.ed. Porto Velho, 2002.

SANQUETTA, C.R. et al. Inventários florestais: planejamento e execução. Curitiba, 2014.

SANQUETTA, C.R. et al. Estimativa da altura e do volume em povoamentos jovens de restauração florestal em Rondônia. BIOFIX Scientific Journal, v.2, n.2, p.23-31, 2017.

SILVA, R.B.; VINHA, E. Vegetação: biodiversidade de espécies florestais. In: Atlas geoambiental de Rondônia. Porto Velho: 
SEDAM, p.96-101, 2002.

SILVA, C.A. et al. Produtividade da Brachiaria brizantha cV. Marandu em função da adubação nitrogenada na Amazônia

Ocidental. Agrarian Academy, v.4, n. 8, p. 201-219, 2017.

Recebido em 01-07-2019

Aceito em 01-10-2019 